\title{
Sensing small molecules with oligonucleotide aptamers.
}

\author{
Jean-Jacques Toulmé*, Eric Dausse, Guillaume Durand, Corinne Ravelet, Eric Peyrin.
}

\begin{abstract}
We developed biosensors in which the detection element is an oligonucleotide -an aptamer- obtained through a combinatorial process. We characterized aptamers specific for different biomarkers. They can be integrated into different devices, allowing their use either in a grafted format or in solution. We developped a multiplex assay signaling the presence of nucleoside derivatives by either surface plasmon resonance or fluorescence anisotropy.
\end{abstract}

Keywords-biosensor, oligonucleotide, aptamer, SPR, fluorescence, pollutant

\section{Introduction}

Aptamers are oligonucleotides identified in large randomly synthesized libraries containing up to $10^{15}$ different oligomers, through in vitro selection, a process known as SELEX (Systematic Evolution of Ligands by EXponantial enrichment). Aptamers have been successfully raised against a wide range of targets: amino acids, nucleic acid bases, proteins, intact viruses and live cells. They generally display a high efficiency of binding thanks to their 3D shape. Aptamer oligonucleotides are easy to synthesize on solid support. They can be chemically modified, conjugated to different pendant groups that provide them with new functionnalities or grafted on various surfaces. They can be considered as valuable alternatives to antibodies.

\section{Results}

We succesfully raised aptamers against synthetic (foldamers) (1) and biological polymers (proteins and nucleic acids). The versatility of aptamer chemistry allows their conversion into tools of biotechnological interest. For instance by conjugating an aptamer to a tecnetium chelating agent we engineered a probe specific for the human matrix metalloprotease 9 (that is overexpressed in tumors) that proved to image sections of glioblastoma by scintigraphy (2).

Toulmé J.J., Dausse E., Durand G.

ARNA Laboratory, Inserm U869, University of Bordeaux

146 rue Leo Saignat, 33076 Bordeaux, France

Peyrin E., Ravelet C.

DPM, CNRS UMR 5063, University Grenoble Alpes

38401 Grenoble, France
We deliberately targeted hairpins in order to identify aptamers that would bind to folded RNA motifs, thus leading to stronger binders than antisense oligonucleotides that should invade the stem-loop structure. Using an innovative screening assay we selected aptamers to primary microRNAs $(3,4)$. The interaction between RNA aptamers and their target hairpin involves the formation of a short Watson Crick helix between complementary loops of the two partners. We identified such an interaction known as "kissing" long ago while looking for aptamers targeted to the trans-active responsive element of HIV-1 (5). We recently revisited this work with the aim of designing a new type of biosensor based on riboswitches. We demonstrated that a RNA-RNA kissing complex is far more stable than the one formed between a RNA hairpin and a linear sequence complementary to the loop (6). We then engineered previously identified aptamers organized as imperfect hairpins in such a way that they switch between folded and unfolded shapes (hence their name aptaswitch) upon binding to their cognate ligand. The folded state is then specifically recognized by a short hairpin (named aptakiss) that engages kissing interactions with the aptaswitch. As the aptakiss does not recognize the unfolded aptaswitch, detection of the aptaswitch-aptakiss complex therefore signals the presence of the ligand in a quantitative manner. We succesfully applied this strategy to the detection of adenosine and GTP by surface plasmon resonance and fluorescence anisotropy (7). We identified a large repertoire of kissing motifs that allows the simultaneous detection of several ligands by different aptaswich-aptakiss complexes. The concept is not restricted to RNA-RNA interactions. We very recently engineered a DNA aptaswitch.

\section{Conclusion}

Aptamers are very promising molecules for different applications. Their versatility is further demonstrated by their activity in organic solutions. This implies the use of chemically modified nucleic acid building blocks, a way that we also explored for increasing the structural diversity (8). This technology is of potential interest for many different areas allowing the detection of drugs, pollutants or contaminants.

\section{References}

[1] 1. Delaurière, L., Dong, Z., Laxmi-Reddy, K., Godde, F., Toulmé*, JJ., Huc*, I. Angewandte Chemie, 2012, 51, 473-477. 
Proc. of the Second Intl. Conf. on Advances in Bio-Informatics and Environmental Engineering - ICABEE 2015

Copyright $\odot$ Institute of Research Engineers and Doctors, USA .All rights reserved.

ISBN: 978-1-63248-043-9 doi: 10.15224/ 978-1-63248-043-9-80

[2] 2. Da Rocha Gomes, S., Miguel, J., Azéma, L., Eimer, S., Ries, C., Dausse, E., Loiseau, H., Allard, M. and Toulmé, J.J. Bioconjug Chem, 2012, 23, 2192-2200.

[3] 3. Dausse, E., Taouji, S., Evadé, L., Di Primo, C., Chevet, E. and Toulmé, J.J. J Nanobiotechnology, 2011, 9, 25.

[4] 4. Evadé, L., Dausse, E., Taouji, S., Daguerre, E., Chevet, E. and Toulmé, J.J. Methods Mol Biol, 2014, in press.

[5] 5. Ducongé, F., Toulmé, J.J. RNA, 1999, 5, 1605-1614

[6] 6. Ducongé, F., C. Di Primo, J. J. Toulmé, J. Biol. Chem., 2000, 275, $21287-21294$

[7] 7. Durand D, Lisi, S, Ravelet C, Dausse E, Peyrin E*, Toulmé JJ* Angewandte Chemie, 2014, 53, 6942-6945.

[8] 8. Bugaut, A., Toulmé, J.J. and Rayner, B. Org Biomol Chem, 2006, 4, 4082-4088 